\title{
Estimate of OEE (Overall Equipment Effectiveness) Objective from Classical OEE
}

\author{
ELHASSAN IRHIRANE*, AHMED BOUNIT and BADR DAKKAK \\ Department of Industrial and Logistical Engineering, \\ National School of Applied Sciences, Cadi-Ayyad university, Marrakech, Morocco
}

(Received on December 30, 2016, Revised on February 10, 2017)

\begin{abstract}
Today, the evaluation of the production systems' performance requires having an appropriate decision-making indicator and to fix its target. The lack of a method to set the target OEE, in accordance with the strategic objectives of the company, is a handicap to guide managers to achieve their individual performance. In this article, we propose a model, based on the method that allows comparison decision criteria pair determining the target of the OEE from the classic OEE. Therefore, this model allows to guide operational decision-makers (maintenance, production, quality,...) to better control their resources and achieve their objective. A case of study was conducted within the mineral water company oulmes (EMO) to test the proposed model. A comparison shows that the offered model provides sure, more definite and better results than the classical approach (based on experience feedback).
\end{abstract}

Keywords: OEE classic, OEE objective, model, method of decision support, strategic objectives

\section{Introduction}

In recent years, many companies are equipped with more complex and sophisticated equipments. What makes them give more importance to the piloting of their performances. The performance improvement is based on identification, measurement and decision-making reduce various losses. These losses relate to unavailability, to nonperformance and to non-quality generated by the manufacturing process. The technological influence is dominant in the production function, but the human factor which will depend on the success of the business plan is fundamental.

The evaluation of the production systems' performance requires having a relevant decision-making indicator and set its target. This strategy allows everyone to understand and target the overall performance, to act on a common reference, understood and shared, to think of customer, to aim at flow (flux) rather than at local output.

For this fact, many works [1], [2], [3] and [4] present the OEE as a major indicator of production systems' performance. Huang and al (2003) presents the OEE as a combination of three factors efficient i.e. the quality, performance and availability [5]. introduced the OEE among the indicators of sustainable development creating added value in companies, but there is no methodology for estimating their predetermined value to reach.

To fix a target is a management act because the choice of the target to be attained orients' the direction performance [6]. The strategic visions can be difficult to communicate, but by distributing the leading objectives into concrete targets of smaller 
size, this will make the management of their transmission process easier. In this way, targets form a critical link between strategy and daily operations [7].

The target of OEE is to be a powerful management tool that can help us develop the action plans we need to better control equipment. The objective can be implemented through objectives of services maintenance, production and quality and the establishment of targets based on the offered model which is an ideal medium to reach. It should be stressed that the absence of a pre-defined approach setting targets of OEE is a handicap to stimulate entrepreneurs to perform better. This is why we seek through this article to know how to determine the target of OEE. The implementation of an effective model to determine the target to reach the OEE allows to control manufacturing process and therefore production efficiency gains, quality and time. Therefore, a model that would be based on a method of decision support seems to be a useful tool for determining the target to reach the OEE.

Our objective in this article is to develop a model calculating the target to be attained of OEE based on the method that allows comparison decision criteria pair. We can fix the objective of OEE by taking into account weights relating to the three main constituents of OEE in the company's strategy. Therefore, providing a synthetic vision to guide operational decision-makers (maintenance, production etc.).

The rest of this article is organized as follows: the following section describes the methodology adopted. A presentation of the model of the standard NF E-60-182 [8] will be presented in section 3. A presentation of the proposed model including the case study will be presented in section 4. Discussion of the comparison between the proposed model and the classical approach is summarized in section 5. Finally, section 6 concludes the article and also gives openings for future work.

\section{Methodology}

In our work, we develop a model calculating the target to be attained of OEE. The objective is therefore to highlight the distribution of weight on the three main constituents of the OEE in the company's strategy to determine the target to fix.

In order to achieve the objective of this work, the followed methodology is going to rest on following stages:

- Step 1 use the model of the standard NF E-60-182 [8] in the calculation of the OEE.

- Step 2 take into account the relative importance of the three main constituents : productivity, the availability and the quality of the model by the use of a method of decision-making

- Step 3 validate the developed model and compare the results with those of the old approach.

\section{Model of the Standard NF E-60-182 (2002)}

The preferred way to calculate OEE is mathematically equivalent to the simple formula described above, but provides a much richer understanding of waste in the manufacturing process by breaking it down into three measurable categories: 
- Availability

- Performance

- Quality

Table 1: Decomposition of time according to AFNOR

\begin{tabular}{|c|c|c|}
\hline \multicolumn{3}{|c|}{ Plant operating time } \\
\hline \multicolumn{2}{|c|}{ Planned production time } & Planned shutdown \\
\hline Operating time & Down time loss \\
\hline Net operating time & Quality Loss \\
\hline Fully productive time & \multicolumn{2}{c|}{ Qoss } \\
\hline
\end{tabular}

Availability

Availability takes into account down time loss, which includes all events that stop planned production for an appreciable length of time (typically several minutes or longer). It is calculated as the ratio of Operating Time to Planned Production Time, where Operating Time is simply Planned Production Time less Down Time:

$$
\text { Availability }=\text { Operating Time } \times \text { Planned Production Time }
$$

\section{Performance}

Performance takes into account speed loss, which includes all factors that cause the production asset to operate at less than the maximum possible speed when running. It is calculated as the ratio of Net Operating Time to Operating Time. In practice, it is calculated as:

$$
\text { Performance }=\text { Ideal Cycle Time } \times \text { Total Pieces/Operating Time }
$$

Ideal Cycle Time is the theoretical fastest possible time to manufacture one piece. Therefore, when it is multiplied by Total Pieces the result is Net Operating Time - the theoretical fastest possible time to manufacture the total quantity of pieces.

\section{Quality}

Quality takes into account quality loss, which factors out manufactured pieces that do not meet quality standards, including pieces that require rework. It is calculated as the ratio of Fully Productive Time (fastest possible time for Good Pieces) to Net Operating Time (fastest possible time for Total Pieces). In practice it is calculated as:

$$
\text { Quality }=\text { Good Pieces } / \text { Total Pieces }
$$

OEE

OEE takes into account all losses (Down Time Loss, Speed Loss, and Quality Loss), resulting in a measure of truly productive manufacturing time. It is calculated as the ratio of Fully Productive Time to Planned Production Time. In practice, it is calculated as:

$$
\mathrm{OEE}=\text { Availability } \mathrm{x} \text { Performance } \mathrm{x} \text { Quality }
$$

\section{Proposed Model}

\subsection{Model Proposed to Set a Target of OEE}

Fixing the target OEE is determined after calculation of the three resulting values of each main component and their corresponding weights. The objective of the OEE is quantified by the following mathematical formula: 


$$
\left\{\begin{array}{c}
\text { OEE }(\text { objective })=\mathrm{P} * \mathrm{w}_{\mathrm{p}}+\mathrm{A} * \mathrm{w}_{\mathrm{a}}+\mathrm{Q} * \mathrm{w}_{\mathrm{q}} \geq \operatorname{OEE}(\text { Classic })(\mathrm{P} * \mathrm{~A} * \mathrm{Q}) \\
\mathrm{w}_{\mathrm{p}}+\mathrm{w}_{\mathrm{a}}+\mathrm{w}_{\mathrm{q}}=1 \\
0 \leq \mathrm{P}, A, Q \leq 1
\end{array}\right\}
$$

$(P, A, Q)$ : Tree main components of the OEE

$\left(\mathrm{w}_{\mathrm{p}}, \mathrm{w}_{\mathrm{a}}, \mathrm{w}_{\mathrm{q}}\right)$ : Relative weights to the main components of the OEE

$O E E$ : Overall Equipment Effectiveness.

These weights are determined through the method of comparison by pair of criteria of decision described as follows:

$\mathrm{X}_{\mathrm{ij}}$ : The importance of the criterion " $\mathrm{i}$ " in relation to the criterion " $\mathrm{j}$ ".

$\mathrm{B}_{3 * 3}$ : The matrix of the three considered criteria: maintenance, production and quality

$$
B_{3 * 3}=\left[\begin{array}{lll}
X_{11} & X_{12} & X_{13} \\
X_{21} & X_{22} & X_{23} \\
X_{31} & X_{32} & X_{33}
\end{array}\right]
$$

Weights are calculated by the standardized geometric average of each line:

$$
\begin{aligned}
G M_{i} & =\left[\prod_{j=1}^{N} X_{i j}\right]^{1 / N} \\
w_{i} & =G M_{i} / \sum_{i=1}^{N} G M_{i}
\end{aligned}
$$

and

$\mathrm{GM}_{\mathrm{i}}$ : The average of the line « $\mathrm{i}$ » and $\mathrm{w}_{\mathrm{i}}$ the weight of the criterion « $\mathrm{i}$ ».

To define $X_{i j}$ (scores), we adopted the approach suggested by [9], which includes two steps:

Step 1: This step consists to represent graphically linguistic variables with their fuzzy sets and to subdivide the universe of discourse [0 i] in a number that varies between two and eleven fuzzy sets and to represent max and min functions to define the score maximum and minimum values.

and

$$
\mu_{\max (x)}= \begin{cases}x & \text { si } 0 \leq x \leq i \\ 0 & \text { sinon }\end{cases}
$$

$$
\mu_{\min (x)}=\left\{\begin{array}{cc}
i-x & \text { si } 0 \leq x \leq i \\
0 & \text { sinon }
\end{array}\right.
$$

The intersection of each membership function with both max and min functions enables us to determine the maximum and minimum values of the score.

and

$$
\begin{aligned}
& \mu_{\mathrm{L}}\left(M_{i}\right)=\operatorname{Sup}_{x}\left(\mu_{\min }(x) \cap \mu_{M_{i}}(x)\right) \\
& \mu_{\mathrm{R}}\left(M_{i}\right)=\operatorname{Sup}_{x}\left(\mu_{\max }(x) \cap \mu_{M_{i}}(x)\right)
\end{aligned}
$$

Step 2: This step converts the verbal judgments (fuzzy sets) into scores (deterministic values). The total score of each fuzzy set is defined by:

$$
\mu_{\mathrm{T}}\left(\mathrm{M}_{\mathrm{i}}\right)=\frac{\mu_{\mathrm{R}}\left(\mathrm{M}_{\mathrm{i}}\right)+1-\mu_{\mathrm{L}}\left(\mathrm{M}_{\mathrm{i}}\right)}{2}
$$

Finally, Table 2 summarizes the scores related to a criterion in relation to another: 
Table 2: The fuzzy Set with their Scores.

\begin{tabular}{cccc}
\hline Linguistic terms & $\mu_{\mathrm{R}}\left(M_{i}\right)$ & $\mu_{\mathrm{L}}\left(M_{i}\right)$ & Score $: \mu_{\mathrm{T}}\left(M_{i}\right)$ \\
\hline$\ldots$. & $\ldots$ & $\ldots$ & $\ldots$ \\
$\cdots \cdots$ & $\cdots$ & $\cdots$ & $\cdots$
\end{tabular}

\subsection{Case study}

The study presented here concerns the blower machine mineral water company Oulmes (EMO) of the site BAHIA Tan-Tan located in the south of Morocco. The latter is responsible for the bottleneck of the production line; and thus illustrates an application of the proposed model. This machine manufactures hollow bodies such as bottles for packaging flat purified water Bahia.

The proposed model is applied in 2 phases:

Phase 1: Setting Scores $\llbracket \mathrm{X} \rrbracket \_$ij

Using the approach described earlier that simplifies the definition of fuzzy sets related to the decision criteria, we can convert the linguistic terms into a score. This approach applies in two steps:

Step 1: To calculate the deterministic values associated with linguistic terms, we have transformed linguistic terms into fuzzy numbers. Given the choice of the scale of type 2, we could calculate the deterministic values "score" linked to the linguistic terms of which values are listed in Table 3.

Step 2: This step consists of converting verbal judgments (fuzzy sets) to scores (deterministic values). It is a way to normalize and to simplify the interpretation of evaluations made by different persons.

Let the fuzzy sets M1 and M2 describe by functions of appearance of triangular type (14) and represented in the Figure 1.

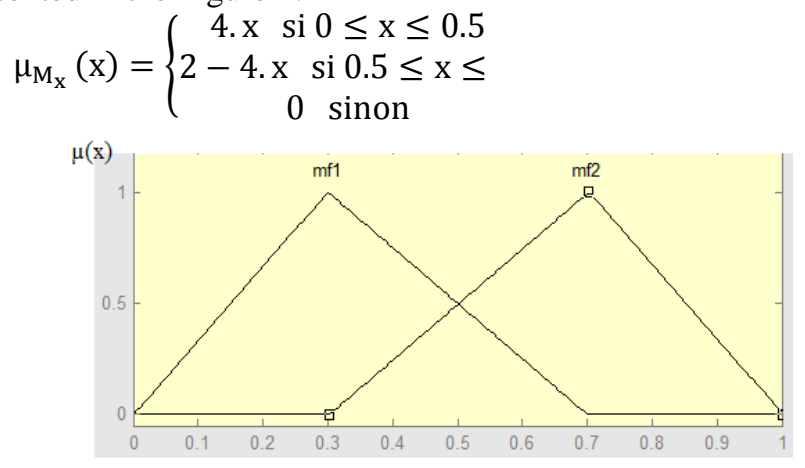

Figure 1: The Membership Functions Corresponding to the 2 Fuzzy Sets

The representations of the max and min functions make it possible to define the maximum and minimum values of the score illustrated in Figure 2. They are defined by taking into account the position of the membership functions on the interval. The intersection of each membership function with the two max and min functions allows us to determine the maximum $\mu_{\mathrm{L}}\left(M_{i}\right)$ and minimal $\mu_{\mathrm{R}}\left(M_{i}\right)$ values of the score and then calculate the total score of each fuzzy set $\mu_{\mathrm{T}}\left(M_{i}\right)$. Finally, Table 3 summarizes the scores to the fuzzy sets. 


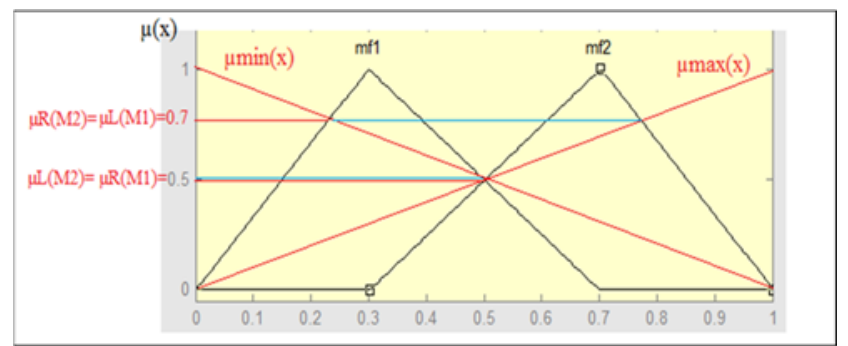

Figure 2: The Minimum and Maximum Scores of the Fuzzy Sets 'M1' And 'M2'

Table 3: Fuzzy Sets and their Corresponding Scores.

\begin{tabular}{ccccc}
\hline Linguistic terms & \multicolumn{1}{c}{ Interpretation } & $\mu_{\mathrm{R}}\left(\mathrm{M}_{\mathrm{i}}\right)$ & $\mu_{\mathrm{L}}\left(\mathrm{M}_{\mathrm{i}}\right)$ & Score: $\mu_{\mathrm{T}}\left(\mathrm{M}_{\mathrm{i}}\right)$ \\
\hline Non-significant & $\begin{array}{c}\text { Criterion is less } \\
\text { important than another } \\
\text { Significant }\end{array}$ & 0.5 & 0.7 & 0.4 \\
$\begin{array}{c}\text { Criterion is more } \\
\text { important than another }\end{array}$ & 0.7 & 0.5 & 0.6 \\
\hline
\end{tabular}

Phase 2: determination of the decision criteria's weight

The strategy of our company considers that quality is less important than the maintenance, the production is more important than the maintenance, the quality is less important than that of production. Taking into account this strategy that is deployed by the company and the scores presented in Table 3, we have extracted the weights of the three criteria using the comparison method by pair of decision criteria.

Let $\mathrm{X}_{\mathrm{ij}}$ : The importance of the criterion "i" in relation to the criterion " $\mathrm{j}$ " and It corresponds to the Score : $\mu_{\mathrm{T}}\left(\mathrm{M}_{\mathrm{i}}\right)$

$\mathrm{B}_{3 * 3}$ : The matrix of the three considered criteria: maintenance, production and quality

$$
B_{3 * 3}=\left[\begin{array}{ccc}
1 & 0.4 & 0.6 \\
0.6 & 1 & 0.6 \\
0.4 & 0.4 & 1
\end{array}\right]
$$

Therefore, the following Table 4 summarizes the weights of the three criteria:

\begin{tabular}{|c|c|c|} 
Table 4: Decision Criteria's Weight \\
\hline Criteria & GMi & Wi \\
\hline Production & 0.63 & 0.34 \\
\hline Maintenance & 0.71 & 0.38 \\
\hline Quality & 0.54 & 0.28 \\
\hline
\end{tabular}

\section{Results and Discussion}

The Overall Equipment Effectiveness (OEE) rate is a means to watch and to ameliorate the effectiveness of our processes of manufacture. The purpose of this article is to calculate the object if OEE of critical machines to guide managers to achieve their individual performance. In order to begin the OEE objective calculation, we begin to collect data on factors such as performance, availability and quality. In order to validate our model of OEE calculate, a comparison was made between the results obtained by the proposed model and those obtained by the classical approach (see Table 5). Using the formula (5), the objective of the OEE of blower machine for the first week is:

OEE (objective) of week $N^{\circ} 1=75 \times 0.34+88.82 \times 0.38+99.77 \times 0.28=87.19$ 
Table 5: Comparison of the Results of the New Model of Calculation of the OEE and those of Classic

\begin{tabular}{|c|c|c|c|c|c|c|}
\hline \multirow{2}{*}{ Week } & \multicolumn{3}{|c|}{ Input } & \multirow[b]{2}{*}{$\begin{array}{c}\text { OEE }= \\
T p \times T d \times T q\end{array}$} & \multirow{2}{*}{$\begin{array}{l}\text { OEE Objective offered } \\
\text { by classical approach }\end{array}$} & \multirow{2}{*}{$\begin{array}{l}\text { OEE Objective } \\
\text { offered by the } \\
\text { proposed model }\end{array}$} \\
\hline & $\mathbf{T p}$ & Td & $\mathbf{T q}$ & & & \\
\hline 1 & $75.00 \%$ & $88.82 \%$ & 99.77\% & $66.46 \%$ & $75.00 \%$ & $87.19 \%$ \\
\hline 2 & $93.90 \%$ & $91.71 \%$ & $99.96 \%$ & $86.09 \%$ & $86.00 \%$ & $94.77 \%$ \\
\hline 3 & $97.97 \%$ & $93.21 \%$ & $99.94 \%$ & $91.27 \%$ & $91.00 \%$ & $96.71 \%$ \\
\hline
\end{tabular}

The analysis of data gathered for the blower machine over a period of three weeks of month shows that the result of the offered model fixes $87,19 \%$ as objective to be attained in second week (close to acquired OEE 86,09\%) counter that of 75,00\% fixed by classical approach. The relevance of the proposed model lies in its ability to help managers to identify the influence of different major losses on OEE and also define important points for organizing resources towards improving the three rates of performance.

It is clear that in the classical approach, the threshold set as an objective of the OEE is not precise enough, because it takes into consideration the OEE output only without seeing the other input elements and their interactions. In addition, it estimates the objective of OEE by the opinion of the experts without the use of a sophisticated method. Another limitation may be shown up; it considers that the three elements of entries have the same weight. Moreover, it is not based on aspects generating losses in the machines. Therefore, the values obtained can be inaccurate and inconsistent with those expected. These can cause conflicts and poor quality within companies.

On the contrary, the offered model allows to overcome all this vagueness. In effect, based on a method of help to decision and taking into account weights relating to the three main constituents of OEE in the strategy of the firm, this model allows to fix the target to be attained of OEE. Therefore, it allows to provide synthetic vision to guide operational decision-makers (maintenance, production, etc). This allows to control equipment and therefore to achieve gains in production efficiency, quality and reducing delays.

The results of the study show that the proposed model will be useful for today's businesses to initiate improvement activities aimed at the proper management of the performance, availability and quality of their equipment. Indeed, it provides complete information on the various losses, at the base of the trends of the three factors of OEE, of a manner stratified to initiate actions appropriated for improvement.

\section{Conclusions}

In this paper, we proposed a model based on a decision support method to calculate the target to be attained of OEE. To illustrate the application of this model, a case study was conducted on the blower machine in plant BAHIA table water of enterprise (EMO). In this study, we have compared, at the same time, the proposed model and the classical approach adopted by the company. The data used in this study were obtained by the technical team. The latter consists of qualified experts working in the use and maintenance of the blower machine. The experimental verification allowed us to verify and to validate the correct functioning of our model. The results show that the proposed model is closer to the real state. Therefore, it allows to guide managers in their choice of action plans which aim at the control of equipment such as the gains in performance, quality and reduction of 
delays. The main prospect of exploitation of this model is to develop by improving the calculation of the OEE.

\section{References}

[1]. Boutry, M. Building of Indicators (http://www.univnancy2.fr/Amphis/images/19/64/Gest- Qual_ConstructionIndicateurs.pdf ) 2007.

[2]. Razzak, M.A., G. Daley, and J.P. Dismukes. Factory Level Metrics: Basis for Productivity Improvement. Proceedings of the International Conference on Modeling and Analysis of Semiconductor Manufacturing (MASM2002), Tempe, Arizona, April 10-12, 2002; 158-162.

[3]. Huang, S.H., J.P. Dismukes, J. Shi, Q.I. Su, M.A. Razzak, R. Bodhale and D.E. Robinson. Manufacturing Productivity Improvement Using Effectiveness Metrics and Simulation Analysis. International Journal of Production Research, 2003; 41(3):513527.

[4]. Kombé,T., E. D. Efaga, B. Ndzana and E. Niel. Efficiency of a system Built on the overall OEE by continuing the reliability diagram. Revue internationale Afrique Science, june 2006; 2(2) : $198-211$.

[5]. Bouziane, M. Introduction of the Overall Equipment Effectiveness (OEE) Among the Indicators of Sustainable Development. International Conference on Energy and Sustainable Development, Alger, November 29-30, 2011; 1-4.

[6]. Jaulent, P. Pertinence of Indicators, Pertinence of Targets: Some Councils. (http://www.finyear.com/Pertinence-des-indicateurs-pertinence-des-ciblesquelquesconseils_a14896.html) 2010.

[7]. Business Link UK. Measure performance and set targets. (http://www.infoentrepreneurs.org/fr/guides/bl---mesure-du-rendement-et-fixation-decibles/\#8) 2009.

[8]. French standard (FS). Means of production - Indicators of performances - Overall Equipment Effectiveness (OEE) - Total Equipment Effectiveness Performance (TEEP) production equipment Effectiveness (PEE). Afnor, French, E-60-182. 2002

[9]. Chen, S.J., C.L. Hwang and F. P. Hwang. Fuzzy Multiple Attribute Decision Making Methods and Applications. Lecture Notes in Economics and Mathematical Systems. Springer-Verlag, Berlin, 1992.

El Hassan IRHIRANE is tenured of doctorate in engineering sciences from the National School of Electricity and Mechanics of Casablanca (ENSEM). Since 2010, he has held a position as a research professor in the Industrial and Logistics Engineering Department of the National School of Applied Sciences in Marrakech. His research work within the 'information systems, logistics and production' team concern the optimization of product design and industrial management systems. E-mail: e.irhirane@uca.ac.ma

Ahmed BOUNIT, Engineer in Industrial Engineering \& Logistics from the National School of Applied Sciences of Marrakech in 2012. Currently doing Ph. D. in engineering sciences, mathematics and computing in Information systems, Logistics and PROduction Laboratory (SyLPRO) from Cadi Ayyad University, Department of the National School of Applied Sciences in Marrakech, Morocco. My research interest is improving the decision-making in production systems' performance and apply it on a industrial company. E-mail:ahmedguelmim@gmail.com

Badr DAKKAK, professor at ENSA Marrakech and Doctor in Industrial Engineering at the Faculty of Sciences and Techniques of Fez. He is the author and co-author of several research papers published in scientific journals and proceedings of international conferences. His research focuses on integrated production systems and skills management. E-mail: badr_dakkak@yahoo.fr 